\title{
Proportional Controller-based Active Suspension System
}

\author{
Kumar M. Senthil, Rajamanickam Ranjith, Gopalan Sankar \\ and Balasubramaniam Sidharth \\ Department of Mechanical Engineering, PSG College of Technology, Coimbatore-641004, India
}

(Received 12 February 2009; accepted 20 August 2009)

The aim of this paper is to develop an active suspension system using a proportional control system. Traditionally, automotive suspension system design has been a compromise between three conflicting criteria: passenger comfort, suspension travel, and road-holding. In conventional suspension systems, a passenger experiences discomfort when a vehicle runs over a bump on the road and vibration is not completely isolated. To overcome this problem, an active suspension system has been developed. A quarter-car model has been used for developing the system, and the hardware-in-loop (HIL) technique is used. In this research, experiments were conducted on both active and passive suspension systems, and performance characteristics were evaluated. It was found that the active suspension is capable of dampening most of the vibrations from the unsprung mass and provides the passenger with the maximum comfort level. The quarter-car model can also be used as a computerized test rig for testing suspension systems in industries.

\section{NOMENCLATURE}

\begin{tabular}{|c|c|}
\hline$U_{c}$ & - Control signal (V) \\
\hline$K_{p}$ & - Proportional gain constant \\
\hline$e(t)$ & - Input error signal $(\mathrm{V})$ \\
\hline$T_{i}$ & - Integral time (sec) \\
\hline$T_{d}$ & - Derivative time (sec) \\
\hline$K_{c r}$ & - Critical gain constant \\
\hline$\omega_{c r}$ & - Frequency of oscillations (rad/sec) \\
\hline$P$ & - Proportional controller \\
\hline$P I$ & - Proportional Integral controller \\
\hline$P I D$ & - Proportional Integral Derivative controller \\
\hline$P_{r}$ & - Pressure exerted by the fluid (N/m2) \\
\hline$F$ & - Force developed in the actuator $(\mathrm{N})$ \\
\hline$A$ & - Area of piston (m2) \\
\hline$M$ & - Mass of the sprung mass $(\mathrm{kg})$ \\
\hline$I$ & - Current (A) \\
\hline$m_{b}$ & - Body mass (kg) \\
\hline$m_{w}$ & - Wheel mass (kg ) \\
\hline$k_{1}$ & - Spring constant (stiffness) of the body $(\mathrm{N} / \mathrm{m})$ \\
\hline$k_{2}$ & - Spring constant (stiffness) of the wheel $(\mathrm{N} / \mathrm{m})$ \\
\hline$f_{a}$ & - Desired force by the cylinder $(\mathrm{N})$ \\
\hline$c_{s}$ & - Damping ratio of the damper $(\mathrm{Ns} / \mathrm{m})$ \\
\hline$z_{r}$ & - Road displacement (m) \\
\hline$z_{b}$ & - Body displacement (m) \\
\hline$z_{w}$ & - Wheel displacements (m) \\
\hline$a$ & - Road height constant (m) \\
\hline
\end{tabular}

\section{INTRODUCTION}

Every moving vehicle on the randomly profiled road is exposed to vibration that is harmful both for the passengers in terms of comfort and for the durability of the vehicle itself. The main task of a vehicle suspension is to ensure ride comfort and road holding for a variety of road conditions and vehicle maneuvers. The active suspension systems are superior in performance to passive suspension systems. But their physical realization and implementation is generally complex and expensive, requir- ing sophisticated electronic operated sensors, actuators, and controllers. Recent advances in adjustable dampers, springs, sensors, and actuators have significantly contributed to the applicability of these systems. Consequently, these automobiles have a better combination of ride and handling characteristics under various conditions than cars with conventional suspension systems.

In this context, it is essential to carry out a detailed study on passive suspension systems and the feasibility of various control systems for the development of active suspension systems to improve performance criteria such as ride comfort and roadholding ability for the various road and load disturbances.

The primary objective of this research is to develop an active suspension system for a passenger car, thereby improving ride comfort. We also compare the responses with passive suspension systems, with respect to the various performance goals such as ride comfort, road-holding ability, and suspension travel (working space of the suspension).

\section{LITERATURE SURVEY}

Active vehicle suspensions have attracted a large number of researchers in the past few decades, and comprehensive surveys on related research are found in publications. ${ }^{1-5}$ These papers classify various suspension systems discussed in literature as passive, active (or fully active), and semi-active systems. In passive systems, the vehicle chassis is supported by only springs and dampers. While in active systems, replacementpartial or full-for the springs and dampers of a passive system are by actuators, these act as force producers according to some control laws, using the feedback from the vehicle. Semi-active suspension systems are considered to be derived from active systems, with the actuator replaced by a controllable damper and a spring in parallel. These employ a feedback control to track the force-demand signal, which is similar to a corresponding active system. The simplest possible, one degree-offreedom (DOF), quarter-car model was investigated. ${ }^{6}$ 